\title{
Increasing life expectancy and the growing elderly population
}

\author{
Helge Brunborg \\ Statistics Norway (SSB), Pb 8131 Dep, NO-0033 Oslo, Norway \\ Helge.Brunborg@ssb.no
}

\begin{abstract}
The life expectancy has increased rapidly in Norway in recent decades, with about $1 / 4$ year per year. The increase has been particularly fast for men, following a temporary decline in the 1950s and 1960s. Statistics Norway's mortality projections using the Lee-Carter method indicate further improvements in this century - about 10 years higher life expectancy at birth. This implies significant mortality declines for older persons as the mortality is now small for young people. With no deaths below age 50 the life expectancy would be only 1-2 years higher.

Population projections are for several reasons important for studying population ageing, including to have knowledge about the future age structure, and to estimate the effects of possible policy changes. In addition, the mortality projections are used for several other purposes than for projecting the population, such as calculating future pensions according to the new pension system, where life expectancy improvements reduce the annual pensions.

The population projections show that the population will age regardless of plausible assumptions made about the demographic components births, deaths, immigration and emigration. Policies to affect these components may only marginally affect future ageing, and in some cases in the wrong direction. The only factor that may significantly affect the future ratio of the working to the non-working population, the potential support ratio, is that people work longer. This ratio will remain at the current level if the pension age is increased from the current 67 years to 78 years at the end of the century. This may be possible if the health of old persons continues to improve.
\end{abstract}

\section{INTRODUCTION}

A population projection is an estimate of the future population of a country, region or the whole world, usually specified by age and sex (at least). Population projections are made by most statistical offices as well as by international organizations (such as the United Nations), research institutions (such as IIASA, International Institute for Applied Systems Analysis) and other. They are used for a variety of purposes. Social and economic planning is one important use and another is to study the consequences of certain trends. Some well-known examples include the "population bomb" projections of the 1960s (1) and the biannual United Nations projections of the world population, showing the implications of the current fertility and mortality trends (http://esa.un.org/unpd/wpp/index.htm). IIASA (2) has made stochastic forecasts of the world population with confidence intervals that illustrate the uncertainty about the future.

Population projections are particularly useful for studying the ageing of the population: First, without projections we would not know the future age composition of the population. Because of projections the coming population ageing has been known for many years. The rapid growth of the number of persons 80 years and older in the 2020s, for example, was already known in the 1970s. In 1979, a growth of 15 per cent of persons 80 and over from 2021 to 2026 was projected (3). The 2012 projections estimated a growth of 22 per cent for this period. The main reason for the higher growth in recent projections is the declining mortality since 1979 for all ages. Hence, the future population development is not certain and this is often illustrated by making alternative sets of assumptions and projection variants. A systematic way of quantifying uncertainty is stochastic population projections $(2,4-6)$.

Second, population projections can be used to study implications for the age structure of possible policy changes: To what extent is it, for example, possible to stop or slow down population ageing by attempting to affect the demographic components, that is: fertility, mortality, immigration and emigration? One issue is the feasibility of policies, such as policies to increase fertility through economic incentives or policies to increase (or decrease) immigration. Another issue is how large the policy effects would be, if any. With regard to the theme of this article, however, it is not likely that policies to slow down mortality improvements to lessen population ageing will be introduced, but indirectly many policy decisions are made that affect life expectancy, such as the size of the health budget and actions to reduce smoking and traffic accidents.

Third, projecting a population requires a forecast or projection of mortality, including the life expectancy. Such projections are also used for other purposes: One example is the estimation of individual old age pensions, which in the reformed Norwegian pension system introduced in 2011 are adjusted for increases in the life expectancy. The social security administration NAV 
uses mortality projections of Statistics Norway in a web based programme where people can find estimates of their own future old-age pension, depending on their age and previous income. A related example is estimation of future pension expenditures, where the microsimulation model MOSART is used (7). Another example is estimation of life insurance tariffs by life insurance companies. A fourth example is the use of estimates of expected remaining years of life in legal divorce and inheritance cases in court. Finally, many people find it interesting to learn how long they can expect to live when future improvements are taken into account.

In this article we will use population projections made by Statistics Norway to study population ageing and the effects of different mortality assumptions. Statistics Norway has a long experience in making population projections, beginning in the 1960s. The projections were for a long time produced and published approximately every three years but have been made annually since 2008, mainly due to the rapid increase in immigration. The projections are now made by age, sex, region (municipality), immigration category, and country background and duration of stay in Norway for immigrants (8). Projections by marital status and household composition were made several years ago $(11,12)$ and recently revised by Alho and Keilman (5). Most of the material in this article has been published previously in Norwegian $(8,9,10)$. The development of mortality and age structure in Norway has been projected by Statistics Norway for a long time and is similar to projections in many other industrial countries, especially the Nordic countries.

\section{METHODS}

The most common method for making population projections is the cohort-component method, which projects a population distributed in groups, usually by age and sex. The method was gradually developed from the end of the $19^{\text {th }}$ century until the middle of the $20^{\text {th }}$ century (13). To project a population we need to make assumptions about the future development of sex- and age-specific fertility, mortality and migration rates (or probabilities). This is usually done by extrapolating observed trends and not by explanatory models. (An exception is the projection of immigration flows to Norway based on an econometric model $(14,15))$. When we project mortality we do not incorporate epidemiological processes, such as cause of death, the influence of obesity and smoking on mortality, or the prospects for longer life through gene technology. These relationships are not well established and it would also be a problem to make good forecasts of these factors (16). Thus, we rely on extrapolating previous mortality trends, as most other projection producers do.

A number of difficult questions arise when we are going to project the mortality to be used in population projections. The general question is for how long and how fast the life expectancy will continue to increase: Will it continue to increase as it has done for about 200 years? Or are we now approaching the end of this golden era? People cannot live forever but it is difficult to tell when the increase will cease. Demographers have repeatedly been wrong on this in the past (17). The mortality decline for infants and children may soon come to an end, as it is now close to zero - but the same has been said before. Further increases in life expectancy require that the death rates of the elderly, especially over age 70, decline substantially. However, the mortality development for the elderly has been uneven, with strong declines for the young elderly but little or no decline for the oldest old (90+).

The methodology for projecting future death rates and life expectancy in Norway has gradually become more sophisticated, both as a result of realizing the complexity and uncertainty of the trends and due to methodological developments (18). In the projections made in the 1960s and 1970s the death rates were kept constant throughout the projection period (19). The reason for this was probably the stagnating life expectancy for males in the $1950 \mathrm{~s}$, as shown in figure 1. A declining mortality trend for the entire projection period was introduced for the first time in the 1987 projection and alternative sets of assumptions about the future development came in 1993. Age- and sex-specific reductions in future death rates that yielded assumed life expectancies were introduced in 1999. Most of these changes were made because it was realized that mortality had been systematically overestimated in population projections, and that there were strong and persistent differences in the age and sex patterns of mortality decline. It is perhaps surprising that it took so long to realise this.

To achieve more systematic forecasts of the future mortality, the Lee-Carter method was introduced in Norway in 2005 (20). This method utilizes long time series of death rates to estimate a small number of parameters for the time trend and the age pattern of mortality (21). The estimates are used to make forecasts of the death rates and consequently of the life expectancy at birth (and at all other ages). The analysis is usually done separately for men and women. The method is used in many countries and provides plausible forecasts of the life expectancy. A weakness of the method is, however, that it is rather sensitive to the choice of observation period: If the observation period is changed the estimates and consequently the forecasts may change significantly. This is illustrated by the graphs in figure 2.

For example, in the first half of the 1900s the mortality decline was particularly rapid for ages below 40, for both sexes, whereas there was little or no change for ages over 80 , see the first panel in figure 1 . It is not clear whether the apparent increase for ages 95-100 is real or due to data issues. During the second half of the past century, the decline was still rapid for children below 10, but there were significant declines for ages 


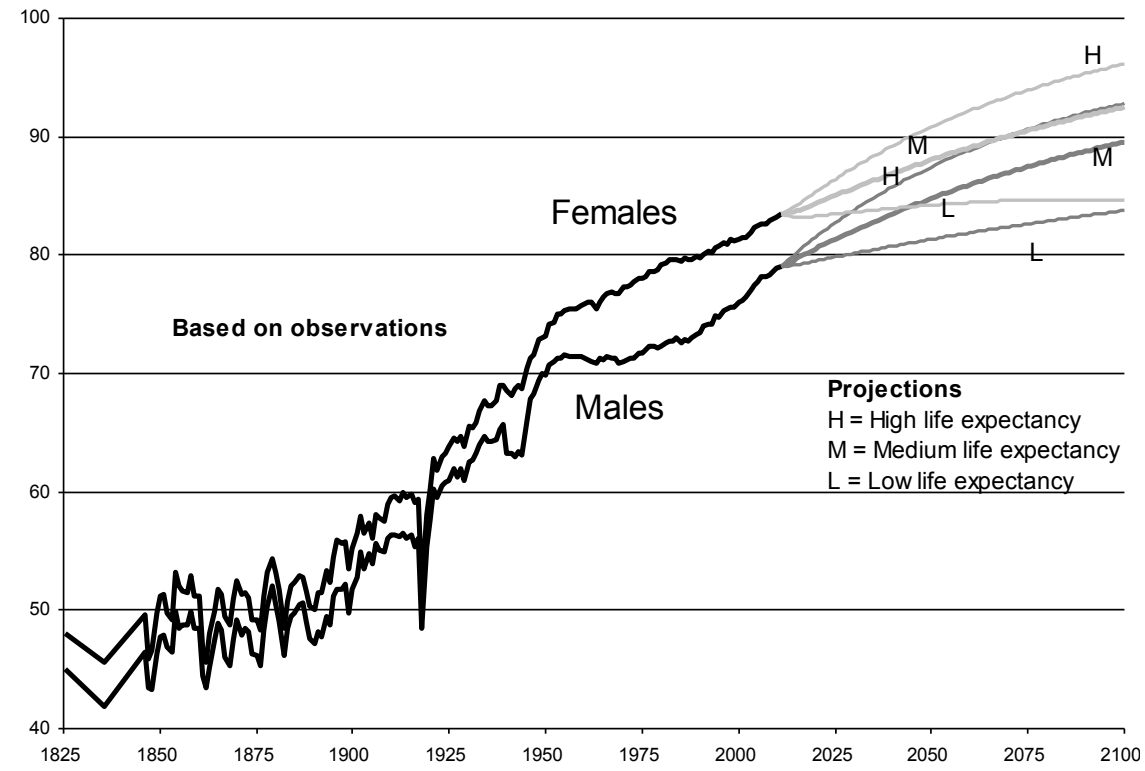

Figure 1. Life expectancy at birth based on observations and projected, 1825-2100. Source: Statistics Norway (36) for 1821-1840 and Mamelund and Borgan (35) for 1846-1994, updated with more recent observations. The estimates for 1821-1840 are only available for ten-year periods and consequently look more regular than estimates for years after 1846, for which annual deaths by age and sex are generally available.

30-90, especially for women, see the second panel. In the first decade or so of the current century, there has been a small but similar decline for men of almost all ages, as shown in the third panel. For women the changes have been more irregular, especially below age 40 , but this is probably due to the small number of deaths in these ages, which may change from year to year due to random factors.

Thus, the choice of the observation period is important for the results, because the age structure of mortality may change over time and because the time trend may be non-linear (22). Using observations since 1900 would underestimate the declining mortality for the elderly when projected into the future. It is, however, possible to adjust the parameters to obtain results that are more in line with other knowledge about mortality trends.

For projections made in the period 2005-2010 all observations available after 1900 were employed, i.e. 1900-2009 for the 2010 projections. However, due to the concerns discussed above only observations since 1950 were used in the most recent projections (made in 2011 and 2012). This may violate some basic projection principles: First, that the observation period should be at least as long as the projection period, and second that "For time series, use all available time periods unless a strong a priori case can be made that a discontinuity has occurred" (23). The introduction of penicillin around 1950 may be seen as representing such a discontinuity. As in previous projections we assume that life expectancy at birth will continue to increase, as it has done steadily for almost two hundred years (17). We use the same mortality estimates for all groups, i.e. immigrants, their children born in Norway, and the population without any immigration background.

\section{RESULTS}

\section{Mortality and life expectancy trends}

The life expectancy at birth has increased from about 45 to about 80 years in the past 200 years (Figure 1). The early increase was mostly related to improved standard of living, including better nutrition, and better public and private hygiene (24). Improved medical services and medical technology, including vaccinations, have gradually played a more important role for the development. In recent years life style changes are contributing significantly to the increasing life expectancy. Smoking is, for example, believed to be the main cause of the decline in male life expectancy in the 1950 s and 1960s. Men started to smoke before women (25) but they also quit smoking before women, which has contributed to a faster increase in life expectancy for men than for women in the past decades. In the past ten years the life expectancy at birth has increased by 2.8 years for men and 1.9 years for women, i.e. a gain of about a quarter of a year per year. This is approximately the same as the gain in the record life expectancy in the world for the past 160 years (17).

Figure 1 also shows the most recent life expectancy projections. In the medium alternative, life expectancy for men is assumed to increase from 79.0 years in 2011 to 89.5 years in 2100 and for women from 83.4 years in 2011 to 92.5 years in 2100 . These levels are very high, especially for men, and much higher than ever recorded in any country in the world. We notice the curvilinear development of the life expectancy, with a slightly slowing growth, due to the properties of the Lee-Carter model. Because of the great uncertainty about the future development, alternative estimates have been made. In the low variant it is assumed that 

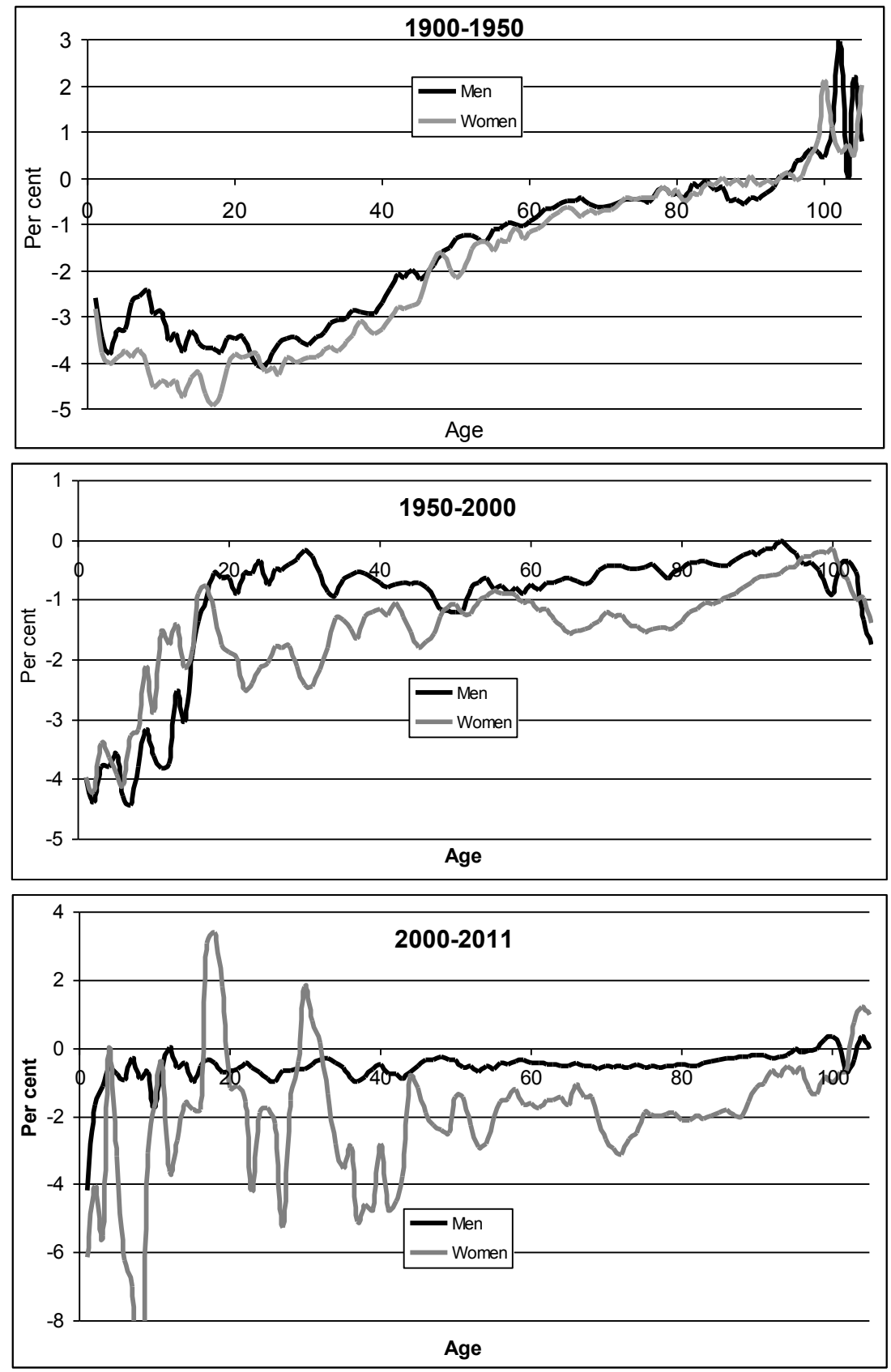

Figure 2. Annual mortality change by sex and age during three time periods, 1900-2011 Per cent decline per year of death probabilities graduated by a 3-term moving average. Source: Mamelund and Borgan (35) updated with more recent observations from Statistics Norway.

life expectancy will increase to 83.8 years for men and 84.6 years for women in 2100 and in the high alternative to 92.8 years for men and 96.1 years for women. The faster growth of the life expectancy for men than for women in recent decades has caused the difference to decline from nearly 7 years in the 1980 s to about 4.5 years in 2011. In the projections this difference is assumed to decline to between 0.8 and 3.3 years in 2100 .

Higher ages have also experienced increasing life expectancies, after the temporary decline for men in the 1950s and the $1960 \mathrm{~s}$, especially for 70 -year olds (Figure 3). A 70-year old man or women can now expect to live until he or she is 86 years (both sexes combined), an increase of 4 years for men and 6 years for women since 1950. Although the increase in life expectancy for older people has been significant in recent years, it has been rather small for the oldest old, especially for 90-year old men, who can now expect to live to 93.8 years, only 0.7 more years than in 1950 , whereas women can expect to live to 94.4 years, 1.2 more years than in 1950. It is not clear why the life expectancy has increased so little for the oldest old. This may be due to selection effects caused by medication and other factors that prevent people from dying at younger ages. Previously, perhaps only the sturdiest survived to such old age. For further increases in the 


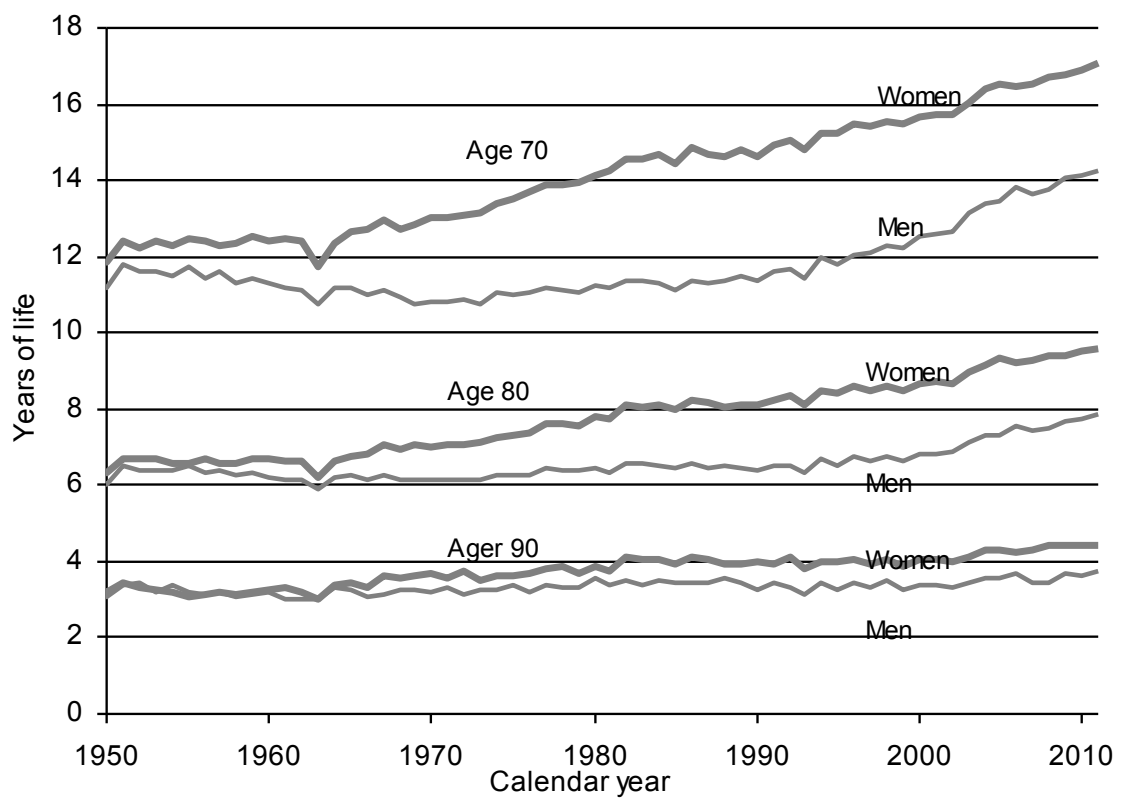

Figure 3. Expected remaining life time at ages 70, 80 and 90 years, 1950-2011. Source: (10).

life expectancy at birth, the mortality of relatively old people would need to decline significantly, as the mortality of young people is now so low that further declines will have little effect on the life expectancy. With no deaths below age 50, for example, the life expectancy at birth would be higher by only 1.9 years for men and 1.2 years for women (based on period life tables for 2011). Based on previous observations and projections we find that cohorts that are now retiring will experience substantially higher life expectancies than those based on the most recent observations of period mortality data. Cohorts born between 1925 and 1942 will probably live 1.5-2 years longer after age 62 than the observations-based period life expectancy at age 62 for these cohorts (26).

\section{Growth of the elderly population}

The demographic transition has played an important role in the ageing of the population, as in all other countries (27). The demographic transition is usually described as a process where death and birth rates pass through four stages: In the pretransitional stage death and birth rates are high and the age structure is young. In the second stage the death rate starts to fall, in Norway about 200 years ago, especially for infants and children, which initially leads to a younger age structure. In the third stage the birth rate begins to fall, in Norway at the end of the $19^{\text {th }}$ century, which leads to an older population. This population ageing is accentuated by declining mortality among adults and the elderly in the fourth stage, where both death and birth rates are low, but not necessarily constant, and the population size grows slowly or declines.

The age distribution of the Norwegian population has undergone significant changes (Figure 4). In 1950, persons aged 67 years and older, made up 7 per cent of the total population. Since then the share has grown to
11 per cent (from 264000 to 654000 persons). For older age groups the trends are even more striking: Persons 80 and older quadrupled from 1950 to 2012 (from 55000 to 220000 ), and persons 90 and older increased by a factor of 8 (from 5000 to 40000 ). The proportion of very old in the total population has also increased significantly: 80 and over from 1.7 to 4.4 per cent, and 90 and over from 0.1 to 0.7 per cent.

The speed of the aging process depends on the measure we look at, i.e., absolute or relative measures, and which ages we consider. These choices again depend on the issues we are interested in. If we are concerned about old age pensions, we should look at ages above 62,67 or 70 . For many health issues ages over 80 are perhaps the most relevant. This age group currently grows rather slowly and may even decline in the next years due to small cohorts born in the 1930s. But in about ten years, when the post war baby boom cohorts are turning 80 , the number of persons over 80 will grow very fast, with 6-7 per cent per year in 20252029 , resulting in a quadrupling in this century (Figure 4). The number of persons over 90 will grow even faster - by a factor of ten before 2100 . In general we observe that the older the age the higher the relative growth: In this century the number of centenarians will increase by a factor of 17 . The uncertainty is large, however, as according to the low-growth variant this number will grow by a factor of "only" 3 and in the high variant by a factor of fully 50 . In absolute numbers, the number of centenarians was 736 at the beginning of 2012 and will grow to 12500 (medium variant) in 2100 . Thus, a rather exotic age group with different needs and challenges is becoming increasingly common.

A summary indicator of the age structure of the population is the old age potential support ratio (PSR), which is defined as the ratio of persons in labour-force 


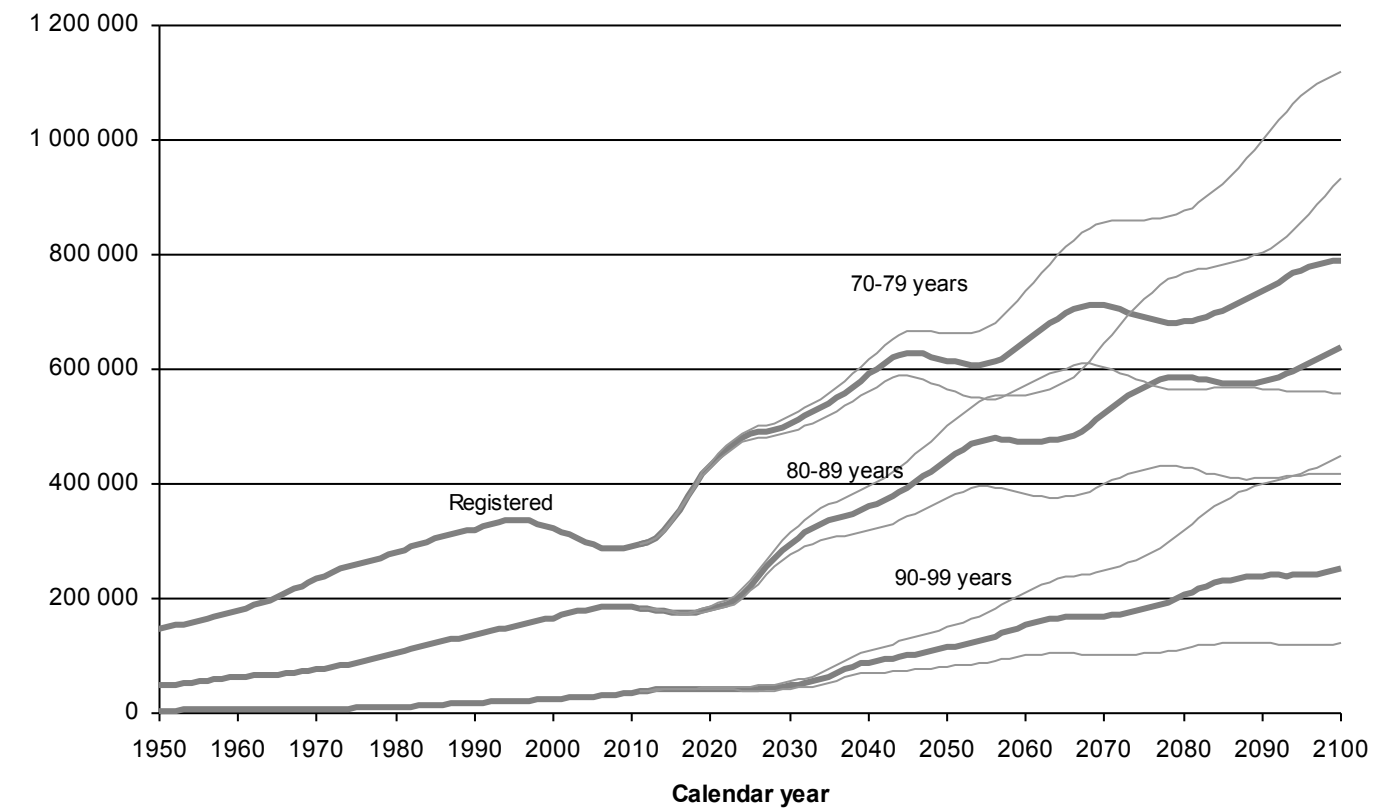

Figure 4. Number of elderly persons in 10-year age groups, 1950-2100. Source: Population projections 20112100: Medium, high and low variant (37).

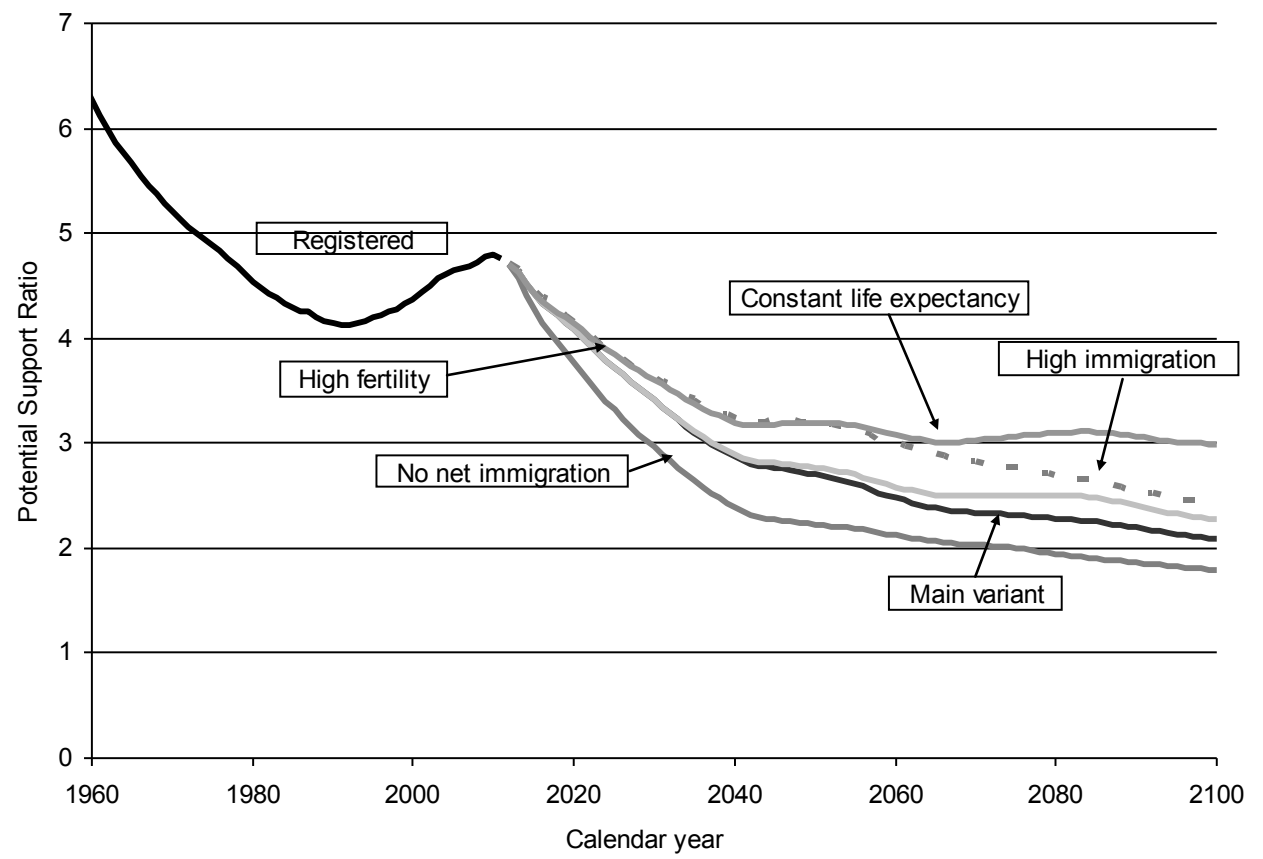

Figure 5. Potential old age support ratio, 1950-2100. Ratio of persons 19-66 to persons 67 and over, population projections 2012-2100 from Statistics Norway.

ages relative to the number of persons in pension ages. This is a pure demographic ratio. There is obviously a substantial number of persons in the labour force who are not working, for various reasons, and many people in the older group who are working. It is nevertheless a useful measure. The PSR is shown in figure 5, where the working ages have been fixed at 20-66 years and the non-working ages to 67 and over (the previous normal pension age in Norway). This ratio is now 4.7, implying that there are roughly 5 persons for each elderly person to provide health and other care to the elderly (as well as providing goods and services to everybody). This ratio will decline to only 2.1 in 2100 , according to the main projection variant.

If the age used to compute the potential support ratio, which can be interpreted as a proxy for the pension age, is increased, the support ratio would increase. What would the pension age have to be to keep the PSR, say, at the 2012 level of 4.7 or higher? (Similar analyses of the retirement age have been done before, see $(28,29)$.) The results from the most recent main projection variant from Statistics Norway shows that the pension age 


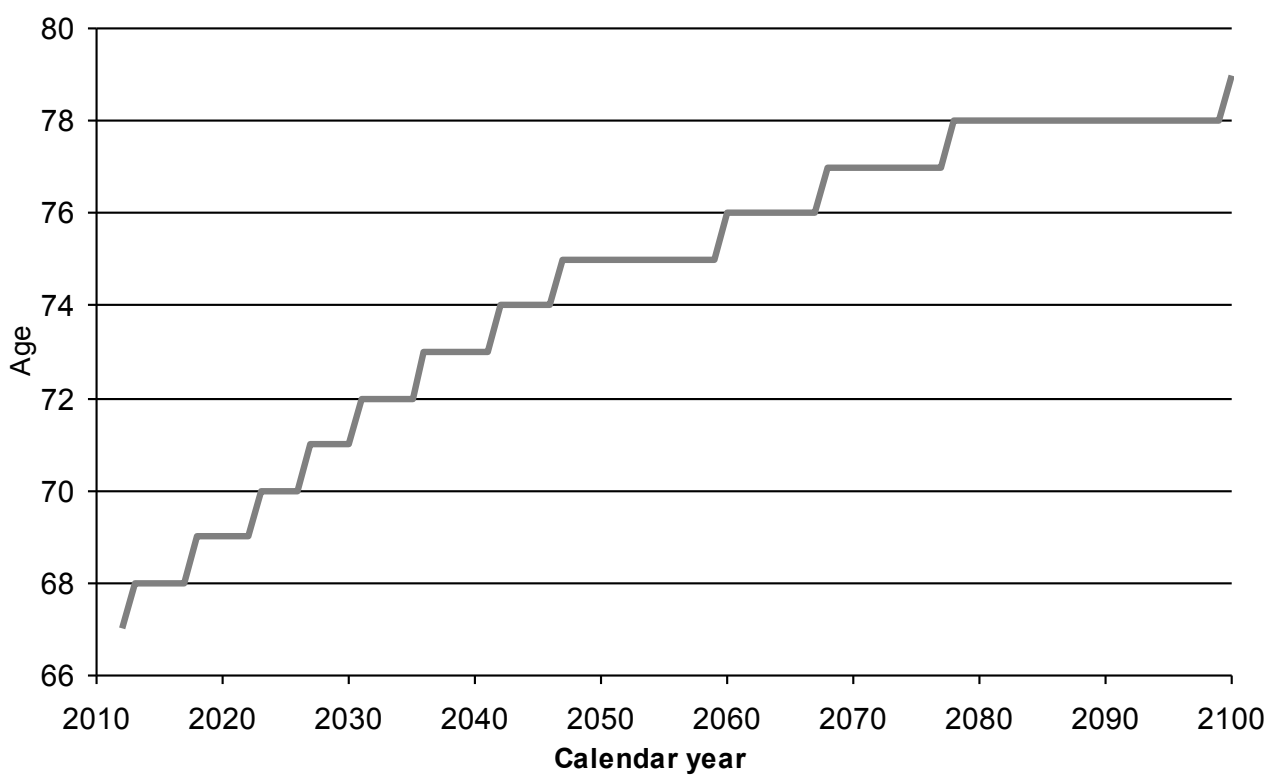

Figure 6. Pension age required to keep the old age potential support ratio at the 2012 level, according to the 2012 main population projection variant from Statistics Norway.

would need to increase to 68 in 2013, 69 in 2018, 70 in 2023 (i.e. to the current maximum pension age), and further to 78 in 2078 and 79 in 2100 , as shown in figure 6. If, on the other hand, the goal would be to keep the PSR at the lowest level ever observed in Norway so far, 4.1 in 1990-1993, the pension age would have to increase to "only" 76 years in 2073 and 77 years in 2096. If, on the other hand, an increasing number of people retire at the minimum pension age of 62 , as introduced in the new pension system in 2011, the support ratio would deteriorate further, to only one person of working age for every person of pension age.

\section{DISCUSSION: WHAT CAN WE LEARN ABOUT POPULATION AGEING FROM POPULATION PROJECTIONS?}

Using population projections from Statistics Norway, we have demonstrated the strong effect of mortality decline on population ageing, both in terms of the number of elderly persons and their proportion of the total population. Several lessons on population ageing may be learned from the population projections presented here.

Past changes in the number of births, especially the low numbers during the depression in the 1930s and the baby boom right after the Second World War and in the 1960s, strongly affect current and future ageing. The number of persons 80 years and older, for example, will decline slightly during the next 4-5 years and begin to rise sharply around 2023, as illustrated in figure 4 . The number of persons 90 years and older, which has never declined due to the continuous improvement in survival, will increase strongly after 2030.

The ageing of the population will occur regardless of the (reasonable) assumptions made about the future trends of the projection components, i.e. fertility, mortality, immigration and emigration. This finding is supported by stochastic population projections for Norway (6), but uncertainty remains about the exact magnitude of the future trends and levels of the age structure. Not surprisingly, mortality trends play an important role in the ageing process. For example, the population projection made in 2005, the first time the Lee-Carter model was used, underestimated the number of persons 80 and over by 8000 in 2012, or 4 per cent, only 7 years later, according to the main variant. From 2012 to 2050 the number of persons 80 years and older will increase from 220000 to 570000 , i.e. more than doubling, according to the most recent main variant. A slower life expectancy improvement would reduce this number by about 100000 and a faster improvement would increase it by 100000 . It is also interesting to look at the rather unrealistic alternative with no life expectancy improvement, i.e. constant mortality. In this case the growth in the number of persons 80 and over is reduced by more than 150000 (or 27 per cent) as compared with the medium variant. The number of persons 80 and over will nevertheless almost double to 2050 .

An important issue is to what degree public policies may stop or reduce population ageing. The potential for doing this through the demographic components is very limited: First, the old age potential support ratio will decline regardless of realistic future paths of the demographic factors determining it. Second, higher fertility and immigration levels will contribute to a slightly younger population and increase the ratio marginally, but not stop the downward trend. Third, policies to stop the immigration surplus will have a significant effect on the support ratio, reducing it to less than 2 , but in an undesirable direction. Fourth, keeping the life expectancy constant would also have a significant effect on 
the PSR, lowering it to "only" 3.5 in 2100 . A policy to stop further mortality reductions is unlikely to get any support, however. Thus, we conclude that there is no demographic solution to the ageing problem.

There is, however, one factor that may make the age distribution less challenging for the welfare state, namely the pension age. The analysis in the present article indicates that a future retirement age of well into the seventies (78 years or more) would be necessary to sustain our current PSR of 4.7. This average retirement age is probably not very realistic, although the improving health among the elderly in the past decades may support a higher pension age in the future than today. However, this "experiment" illustrates how important it is that people stay longer in the work force. Retiring later is not only good for the ratio of the working to the non-working population. It has also been shown that persons who retire late have lower mortality than persons who retire early (30). Note that the interpretation of this pension age is de facto or average pension age, not the formal pension age. The actual pension age in 2005 has been estimated at only 63.1 years (31), which is 4 years less than the general pension age of 67 and one year more than the early retirement age of 62 , which all employees in the public sector and about half the employees in the private sector were entitled to. If an increasing number of people would retire earlier (e.g. at the minimum pension age of 62 ), the support ratio would deteriorate further. This would pose direct challenges to the sustainability of the Norwegian welfare state (33).

Although it is certain that there will be rapid population ageing in the future, there remains considerable uncertainty about the actual levels of ageing due to a lack of understanding of mortality trends and differentials according to region and social class. In Norway, the life expectancy difference between the counties of Sogn \& Fjordane and Finnmark is 3-4 years for males and 3 years for females, and it has been like this for at least 30-40 years. For the boroughs of Oslo there are large differences between the life expectancy in the inner city (such as Sagene) and the suburban parts (such as Vestre Aker), with an estimated difference of up to 12 years for males. There are also significant social class differences in life expectancy that do not seem to vanish, such as by occupation $(34,35)$ and education. An important question therefore remains: Can we achieve substantial future life expectancy increases without first reducing regional and social class differences? If we want to keep up the Norwegian welfare state at the current level, for people of all ages, it looks like the only solution would be to improve the health of the elderly, which is an important goal in itself, and to stimulate people to work longer.

\section{ACKNOWLEDGEMENTS}

I am grateful to the editors and the anonymous referee for valuable comments.

\section{REFERENCES}

1. Ehrlich P. The Population Bomb. New York: Ballantine Books, 1968.

2. IIASA. A world of simultaneous population growth and shrinking unified by accelerating aging. Popnet 2007/08; 39: 1-3.

3. Central Bureau of Statistics. Population Projections 1979-2025. Regional Figures. NOS B82, Oslo, 1979.

4. Alders M, Keilman N, Cruijsen H. Assumptions for long-term stochastic population forecasts in 18 European countries. Eur J Population 2007; 23: 33-69.

5. Alho J, Keilman N. On future household structure. J R Stat Soc [A] 2010; 173 (1): 117-143.

6. Foss AH. Stokastiske befolkningsprognoser for Norge 2012-2060. Økonomiske analyser 2/2012: 30-34.

7. Fredriksen D, Gunness T, Stølen NM. Oppdaterte framskrivinger av arbeidsstyrke, pensjonsutgifter og finansieringsbyrde. Økonomiske analyser 4/2008: 36-43.

8. Brunborg H, Texmon I, Tønnessen M. Befolkningsframskrivninger 2012-2100: Modeller og forutsetninger. Økonomiske analyser 4/2012: 32-40.

9. Brunborg H, Texmon I, Tønnessen M. Befolkningsframskrivninger 2012-2100: Resultater. Økonomiske analyser 4/2012: 53-58.

10. Brunborg H, Tønnessen M. Befolkningsutviklingen. Økonomiske analyser 2/2012: 3-11.

11. Brunborg H, Mønnesland J, Selmer R. Projections of the population by marital status 1979-2025. Rapport 81/12, Statistics Norway, Oslo, 1981.

12. Keilman N, Brunborg H. Household projections for Norway, 1990-20 Part I: Macrosimulations. Report 95/21, Statistics Norway, Oslo, 1995.

13. O’Neill BC, Lutz W. Projections and forecasts, population. In: Demeny P, McNicoll G (eds.). The encyclopedia of Population, Vol. 2. New York: MacMillan Reference, 2003: 808-813.

14. Brunborg H, Cappelen Å. Forecasting migration flows to and from Norway using an econometric model. Work Session on Demographic Projections. Eurostat Methodological Working Papers, 2010: 321-344.

15. Tønnessen M, Brunborg M, Cappelen Å, Skjerpen T, Texmon I. Inn- og utvandring. Økonomiske analyser 4/2012: 41-52. 
16. Tabeau E, Jeths AvdB, Heathcote C. Forecasting Mortality in Developed Countries. Dordrecht: Kluwer, 2001.

17. Oeppen J, Vaupel JW. Broken limits to life expectancy. Science 2002; 296 (5570): 1029-1031.

18. Brunborg H. Mortality projections in Norway. In: Bengtsson T, Keilman N (eds.): Perspectives in Mortality Forecasting: I. Current Practice. Social Insurance Studies No. 1, Swedish National Social Insurance Board, Stockholm, 2003: 41-58.

19. Sosialdepartementet. Innstilling fra Pensjonsutredningskomitéen av 1962. Oslo, 1963.

20. Keilman N, Pham DQ. Hvor lenge kommer vi til å leve? Levealder og aldersmønster for dødeligheten $\mathrm{i}$ Norge, 1900-2060. Økonomiske analyser 6/2005: 43-49.

21. Lee R, Carter L. Modeling and forecasting U.S. mortality. J Am Stat Assoc 1992; 87 (419): 659-75.

22. Booth H, Maindonald J, Smith L. Applying Lee-Carter under conditions of variable mortality decline. Population Studies 2002; 56: 325-336.

23. Armstrong JS (ed.). Principles of forecasting: a handbook for researchers and practitioners. Springer, 2001.

24. Schofield R, Reher D. The decline of mortality in Europe. In: Schofield R, Reher D, Bideau A (eds.): The Decline of Mortality in Europe. Oxford: Clarendon Press, 1991.

25. Pampel FC. Cigarette use and the narrowing sex differential in mortality. Population and Development Review 2002; 28 (1): 77-104.

26. Brunborg H, Fredriksen D, Stølen NM, Texmon I. Levealdersutvikling og delingstall. Økonomiske analyser 4/2008: 27-35.

27. Casterline JB. Demographic transition Encyclopedia of Population. In: Demeny P, McNicoll G (eds.). The encyclopedia of Population, Vol. 1. New York: MacMillan Reference, 2003: 210-216.

28. Lannoy F, Lipszyc B. Le vieillissement en Belgique: données démographiques et implications économiques. In: Pestieau, Gevers, Ginsburgh, Schokkaert, Cantillon (eds.). Réflexions sur l'avenir de nos retraites. Garant, Leuven, 2000: 11-36.

29. Calot G. French demographic perspectives. Futures 1986; 18 (2): 242-257.

30. Skirbekk V, Telle K, Nymoen E, Brunborg H. Retirement and mortality in Norway - Is there a real connection? In: Salzmann T, Skirbekk V, Weiberg M (eds.). Wirtschaftpolitisch Herausforderungen des demografischen Wandels. Wiesbaden: VS Research; 2010: 201-222.

31. Bø TP. Arbeidstiden - mønstre og utviklingstrekk. Rapporter 2008/12. Statistisk sentralbyrå.

32. Bjørnstad R, Gjelsvik ML, Holm I, Holmøy E, Nielsen VO, Stølen NM, Texmon I. Kan behovet for helse- og omsorgstjenester dekkes? Økonomiske analyser 6/2009: 33-41.

33. Borgan JK. Prester og fysioterapeuter lever lengst. Samfunnsspeilet 3/2004: 2-8.

34. Borgan JK. Høyest dødelighet blant ufaglærte menn. Samfunnsspeilet 3/2007: 7-13.

35. Mamelund S-E, Borgan J-K. Kohort- og periodedødelighet $i$ Norge 1846-1994. Rapporter 96/9, Statistics Norway, Oslo, 1996.

36. Statistics Norway. Historical statistics. NOS C 188. Oslo, 1964.

37. Brunborg H, Texmon I. Befolkningsframskrivning 2011-2100: Nasjonale resultater. Økonomiske analyser 4/2011: 46-51. 